\title{
The Influences of Iron Ore Tailings as Fine Aggregate on the Strength of Ultra-High Performance Concrete
}

\author{
Zhigang Zhu, Beixing Li, and Mingkai Zhou \\ State Key Laboratory of Silicate Materials for Architecture, Wuhan University of Technology, Wuhan 430070, China \\ Correspondence should be addressed to Beixing Li; libx0212@126.com
}

Received 16 March 2015; Accepted 30 August 2015

Academic Editor: João M. P. Q. Delgado

Copyright (c) 2015 Zhigang Zhu et al. This is an open access article distributed under the Creative Commons Attribution License, which permits unrestricted use, distribution, and reproduction in any medium, provided the original work is properly cited.

\begin{abstract}
The present study looks for the feasibility of preparing UHPC with iron ore tailings (IOT for short) as fine aggregate. To enhance outstanding high performances, some influences on UHPC mortars were investigated such as different kinds of sands, different mix ratio of sands, and different largest particle size of fine aggregate. The results show that IOT have negligible poorer aggregate performance than silica sands but better than river sands. The strength of UHPC reaches the highest point when silica sands were instead $60 \%$ by IOT. As the largest particle size of fine aggregate is decreasing, the strength and frost resistance of UHPC were improved, but the liquidity was decreased. Micropowder of IOT affects the strength and the optimal content was $4 \%$.
\end{abstract}

\section{Introduction}

Reactive Powder Concrete (RPC for short) was a new type of concrete which came forward by French scholars named Richard and Cheyrezy [1] in the 1990s; academic admiral calls it ultra-high performance concrete (UHPC for short) for RPC is a kind of invention patent. It has ultra-high strength, high toughness, and low porosity. In order to get high strength and high durability, the basic principle of preparation is reducing materials' internal defects (porosity and microcracks) to the minimum by improving the composition of fineness and activity. Active components are composed of cement, silica powder, and fly ash; the particle size of them is $0.1 \mu \mathrm{m} \sim 1 \mathrm{~mm}$.

In recent years, UHPC has been successfully applied to many special structures; Frenchmen have reformed cooling towers of a nuclear power plant by UHPC [2], Americans have used it in sewage works [3], and Canadians have built a footbridge by adopting UHPC prefabricated structures [4]. However the high cost of UHPC and the shortage resource of silica sands are the disadvantages restricting its wider usage; looking for a kind of ecological recycle resource to replace silica sands as aggregate is necessary.

IOT is a class of castoff after mineral processing and composite mineral raw material; in addition to containing a small amount of metal, its main mineral components are the gangue minerals such as quartz, pyroxene, feldspar, garnet, hornblende, and alteration minerals. China as ironmaking powers after the reforming and opening to the outside world, rapid development of mining leading to the deposition of IOT which was nearly 5 billion tons till 2010 , accounts for $50 \%$ of the total tailings [1,5-9]. The management of iron ore tailings not only needs a lot of money, but also can cause serious impacts on the environment; how to turn it into treasure is imminent. At present, the IOT has been widely used in building materials in China but does not solve the low level utilization.

In this paper, IOT are investigated as a potential fine aggregate replacing silica sands and a recycling resource to ensure the greenness, mechanical performance, and working performance of UHPC. The researches focus on how some important aspects of IOT as fine aggregate affect UHPC.

\section{Experimental Program}

2.1. Raw Materials. Ordinary Portland cement has a strength class of $52.5 \mathrm{MPa}$ at $28 \mathrm{~d}$. Fly ash has a specific surface area of $6000 \mathrm{~cm}^{2} / \mathrm{g}$. Slag powder has a specific surface area of $4500 \mathrm{~cm}^{2} / \mathrm{g}$ and silica fume has a specific surface area of $224000 \mathrm{~cm}^{2} / \mathrm{g}$. The chemical properties of the materials are given in Table 1. 
TABLE 1: Chemical component (\%).

\begin{tabular}{lccccccccc}
\hline Name & $\mathrm{SiO}_{2}$ & $\mathrm{Al}_{2} \mathrm{O}_{3}$ & $\mathrm{CaO}$ & $\mathrm{MgO}$ & $\mathrm{SO}_{3}$ & $\mathrm{Fe}_{2} \mathrm{O}_{3}$ & $\mathrm{Na}_{2} \mathrm{O}$ & $\mathrm{K}_{2} \mathrm{O}$ & Loss \\
\hline Cement & 20.71 & 4.97 & 59.88 & 2.33 & 3.72 & 3.26 & $/$ & 3.62 \\
IOT & 68.44 & 8.27 & 4.46 & 3.04 & 0.35 & 7.46 & 2.29 & 1.90 & 2.73 \\
Fly ash & 55.77 & 31.77 & 2.59 & 0.61 & 0.60 & 3.88 & $/$ & 1.03 \\
Slag powder & 32.69 & 15.50 & 38.14 & 9.14 & 1.73 & 1.70 & 0.10 & 0.43 & 2.3 \\
Silica fume & 94.32 & 0.14 & 0.06 & 0.05 & 0.43 & 1.29 & $/$ & $/$ \\
\hline
\end{tabular}

TABLE 2: Physical properties of three kinds of sands (\%).

\begin{tabular}{|c|c|c|c|c|c|c|}
\hline Name & Clay lump & Water absorption & Roughness & Crushing value & Robustness & MB \\
\hline IOT & 0 & 0.9 & 14.2 & 11 & 7.8 & 0.3 \\
\hline Silica sands & 0 & 0.6 & 10.7 & 10 & 5.8 & 0 \\
\hline River sands & 0.7 & 0.8 & 12.4 & 13 & 6.2 & 0.8 \\
\hline
\end{tabular}

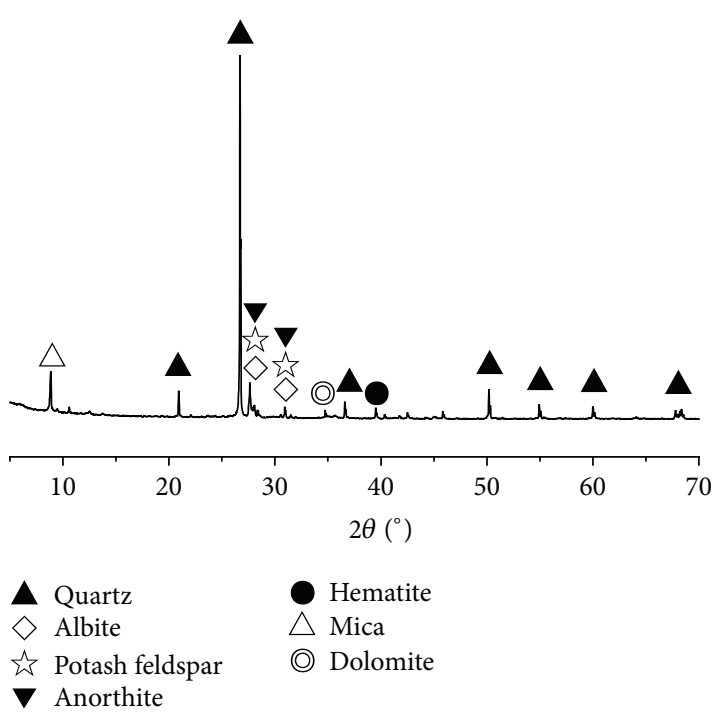

FIGURE 1: XRD of IOT.

IOT, silica sands, and natural sands were used as fine aggregate whose size range is from $0.075 \mathrm{~mm}$ to $4.75 \mathrm{~mm}$ without micropowder. The apparent density of cleaned IOT is $2.62 \mathrm{~g} / \mathrm{cm}^{3}$, the apparent density of silica sands with the same grading as IOT is $2.64 / \mathrm{cm}^{3}$, and the apparent density of river sand is $2.61 \mathrm{~g} / \mathrm{cm}^{3}$. The XRD pattern of IOT is given in Figure 1, their grading curve is given in Figure 2, and their physical properties are given in Table 2.

A polycarboxylate-based superplasticizer was used whose solid content is $30 \%$ and water reducing rate is about $30 \%$. The mixing water was potable tap water. The steel fiber coated by copper has a diameter of $0.22 \mathrm{~mm}$, length of $12 \sim 14 \mathrm{~mm}$, tensile strength about $2900 \mathrm{MPa}$, elastic modulus of $200 \mathrm{GPa}$, and density of $7.8 \mathrm{~g} / \mathrm{cm}^{3}$.

2.2. Mix Proportions and Specimen Preparation. The mix of UHPC is given in Table 3. Cementitious materials were mixed at a low speed for $3 \mathrm{~min}$ in forced mortar mixing pot; then IOT were added and mixed for $3 \mathrm{~min}$; after that water and

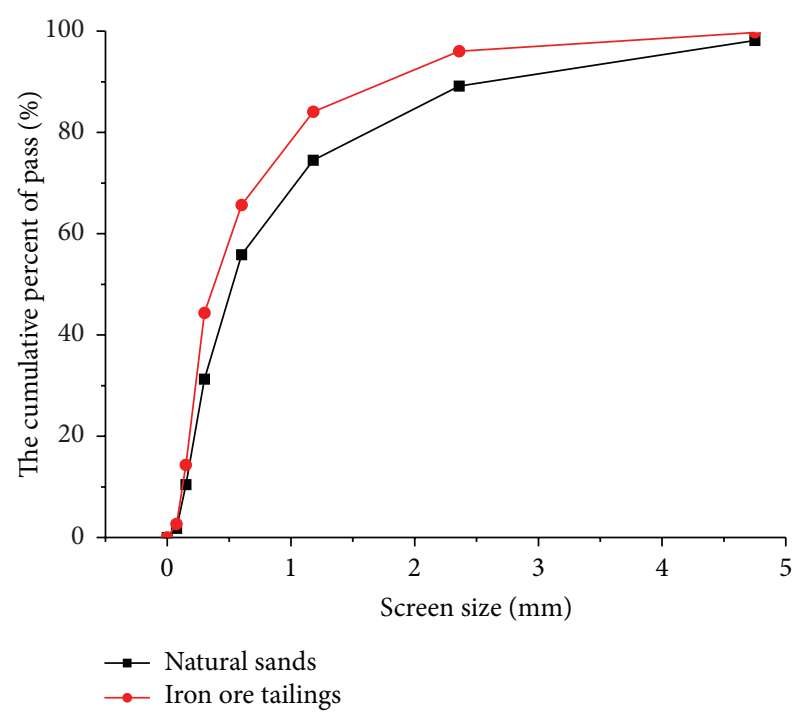

FIGURE 2: Grading curve of sands.

steel fiber were poured into the pot and mixed at a high speed for $3 \mathrm{~min}$; at last, water reducing agent was added and mixed at the high speed for another $3 \mathrm{~min}$ and then put into molds with a size of $40 \times 40 \times 160 \mathrm{~mm}$ and on a high-frequency vibration machine for about $90 \mathrm{~s}$ to eliminate the inner air.

All the UHPC mortars were demolded after curing in a standard room with about $20^{\circ} \mathrm{C}$ and relative humidity $95 \%$ or more for $24 \mathrm{~h}$. Then the specimen was cured in the $100^{\circ} \mathrm{C}$ hot water for $48 \mathrm{~h}$ (heating and cooling velocities are below $20^{\circ} \mathrm{C} / \mathrm{h}$ ); at last the specimen was cured in $20^{\circ} \mathrm{C}$ water for a certain time.

2.3. Test Methods. The fresh UHPC mortars were tested for the flowability according to Chinese Standard GB/T24192005. The strength was tested by Chinese Standard GB/T17671-1999. Aggregate and cement paste transition zone were observed by Germany's field emission scanning electron microscope named Zeiss Ultra Plus. 
TABle 3: The mix of UHPC (kg).

\begin{tabular}{lccccccc}
\hline Water & Sand & Cement & Fly ash & Slag powder & Silica fume & Water reducer & Steel fiber \\
\hline 178 & 1111 & 667 & 167 & 167 & 111 & 22 & 120 \\
\hline
\end{tabular}
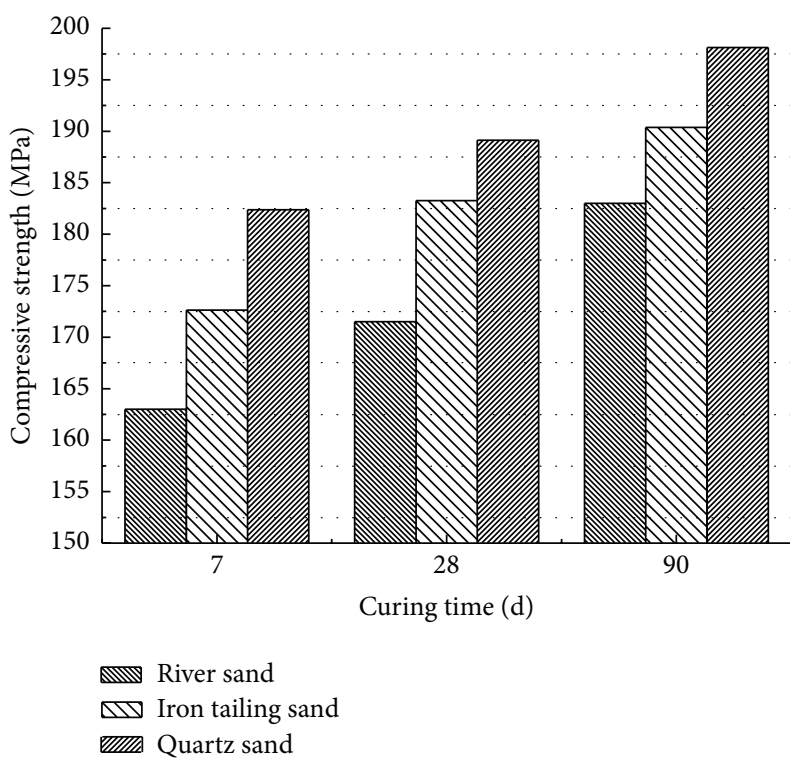

(a) Compressive strength
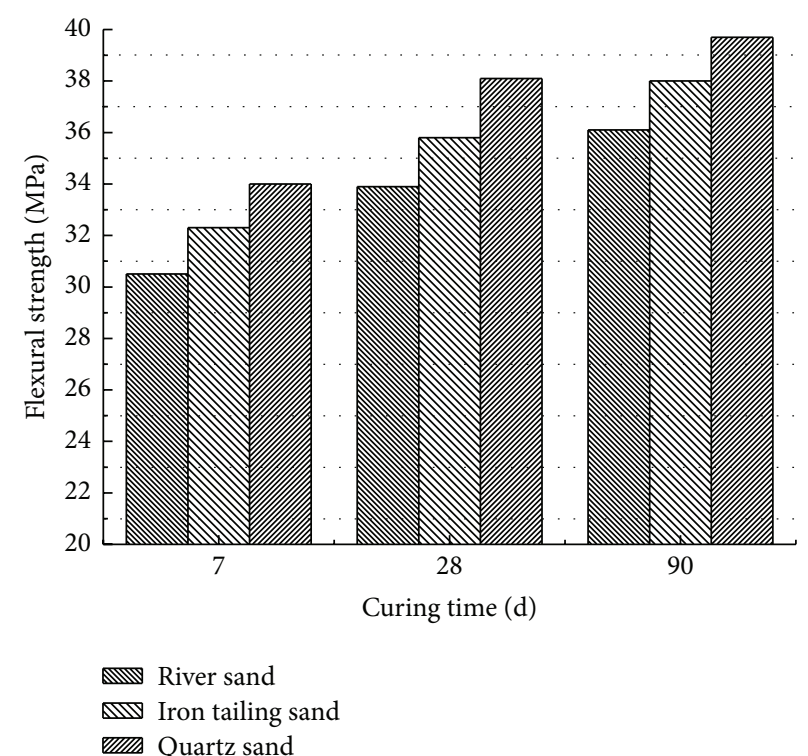

(b) Flexural strength

FIGURE 3: The influence of different sands on strength.

\section{Results and Discussion}

3.1. Influence of Different Sands on the Strength of UHPC. The influences of different sands on the strength of UHPC mortars are presented in Figure 3. The result shows that the strength increased with curing age for the specimen, the $7 \mathrm{~d}$ strength of concrete was nearly $90 \%$ to the $90 \mathrm{~d}$ strength, and the $28 \mathrm{~d}$ strength decreased no more than $8 \%$ for all the $90 \mathrm{~d}$ specimen. It can be explained by the fact that the heat water curing accelerates the hydration of cementing materials and the activity of volcanic material which leads to the fact that UHPC can have a very high strength.

It also can be seen that UHPC of silica sands had the highest strength and the river sands were the lowest. The surface of silica sand is clean and particle shape is spherical, particle shape of IOT is not better than natural sands because they are made by crusher, and they have smaller particles which can be seen in Figure 2. The small particles play a role of "microfilling" effect which can increase the compactness of UHPC and make up for the inadequacy of particle shape. UHPC with river sands, IOT, and quartz sands has an appearance density of $2459 \mathrm{~kg} / \mathrm{m}^{3}, 2471 \mathrm{~kg} / \mathrm{m}^{3}$, and $2503 \mathrm{~kg} / \mathrm{m}^{3}$, respectively, according to tests, showing the same result as strength.

3.2. Influence of Different Size on the Strength of UHPC. Figure 4 is about the influence of aggregate size of IOT against strength and the biggest size is decreased from $4.75 \mathrm{~mm}$ to $0.6 \mathrm{~mm}$. It can be seen that intensity had an obvious increase with the decrease of aggregate size for the same curing age; the growth ratio was small with the increase of curing time. It is well known that the concrete is composed of aggregates, cement slurry, and the transition zone; the transition zone is the weakest part in concrete; Akçaoğlu et al. [10] research has shown that the difference of elasticity modulus between aggregate and cement paste matrix is bigger with the increase of aggregate size leading to stress concentration in the transitional zone and causing more microcracks near aggregate.

However, the bigger the aggregate size, the lower the strength of transition zone and it results in the decrease of strength of concrete as a whole. Figures 5(a)-5(d) present SEM images expanded 1000 times with maximum particle size of IOT decreasing from $4.75 \mathrm{~mm}$ to $0.6 \mathrm{~mm}$ for curing $28 \mathrm{~d}$. Aggregate and cement paste transition zone can be seen from the diagram; there are obvious and broad connecting cracks in Figure 5(a); Figure 5(b) also has a very long crack but the width is significantly less than Figure 5(a); there is a very short narrow crack and the crack is disconnected which can be seen in Figure 5(c); in Figure 5(d), the aggregate and cement paste well bond together as a whole; the fracture of transition zone cannot be seen nearly.

From above results, the compressive strength is nearly five times the flexural strength no matter which aggregate was used. However, UHPC is famous for its high compressive strength and excellent work performance; the rest of the paper only shows the compressive strength and regards the flexural strength which is $20 \%$ of the compressive strength. 


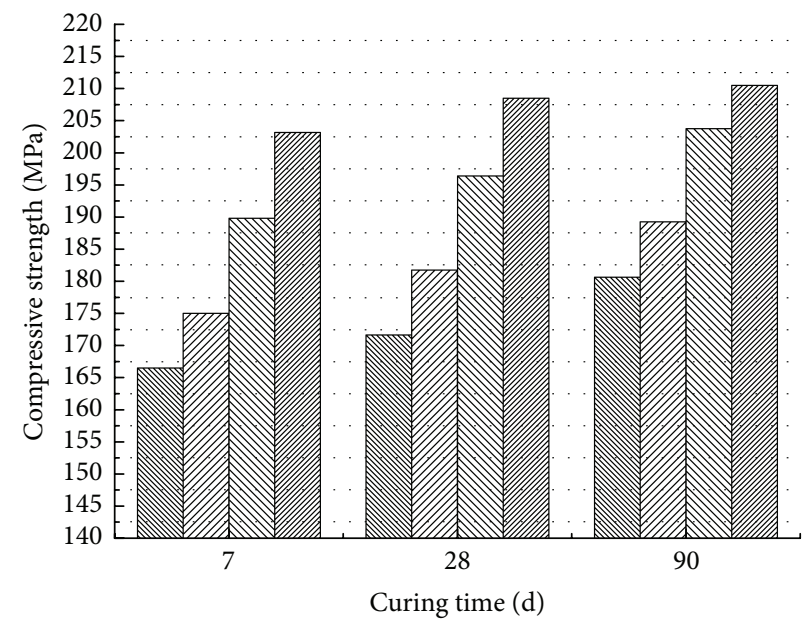

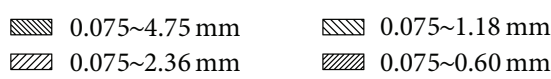

(a) Compressive strength

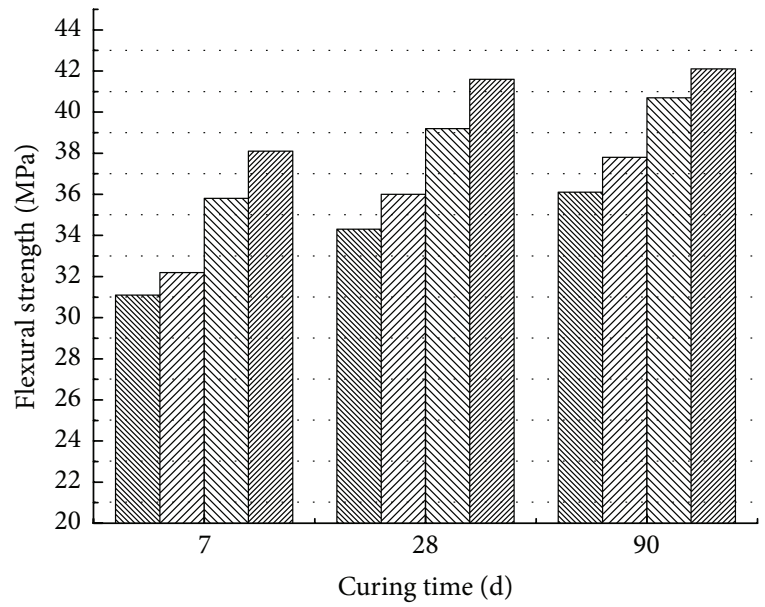

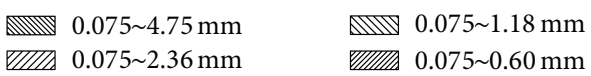

(b) Flexural strength

FIGURE 4: The influence of aggregate size on strength.

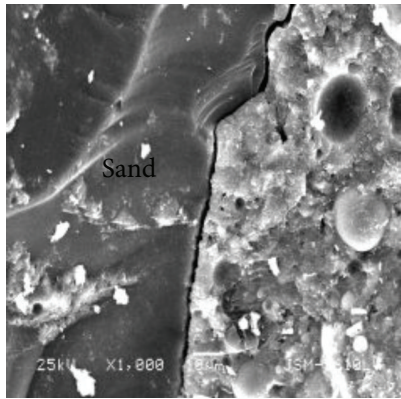

(a) $4.75 \mathrm{~mm}$

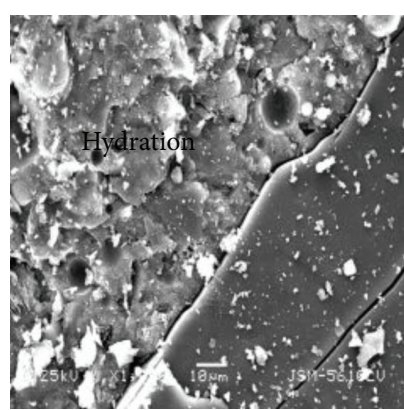

(b) $2.36 \mathrm{~mm}$

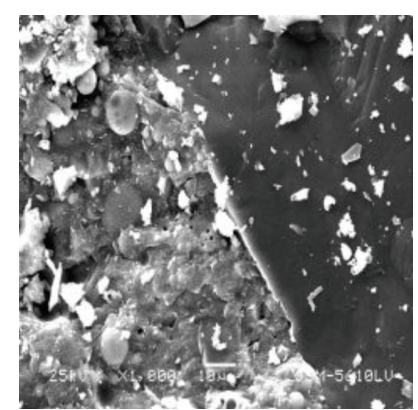

(c) $1.18 \mathrm{~mm}$

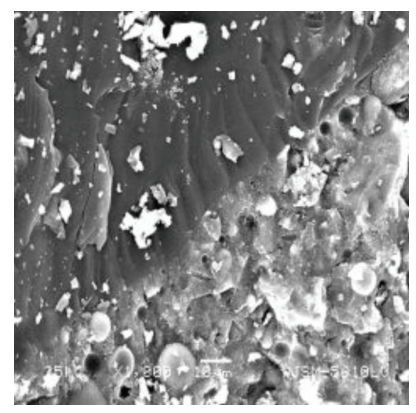

(d) $0.6 \mathrm{~mm}$

FIGURE 5: SEM of interfacial transition zone $\times 1000$.

3.3. Influence of Different Replacement on the Strength of UHPC. From above results, the aggregate performance of IOT is poorer than silica sands at the same particle size distribution, $84 \%$ of the quality of IOT particles distributes in $0.075 \sim 1.18 \mathrm{~mm}$, and of course compressive strength of concrete is higher with particles decreased; it is necessary and valuable to study the feasibility using IOT distributed in $0.075 \sim 1.18 \mathrm{~mm}$ to replace silica sands and prepare UHPC.

Figure 6 shows the influence of different replacement against UHPC mortars using $0 \sim 1.18 \mathrm{~mm}$ IOT instead of silica sands under different curing time. From the three lines we can see that they have the same changing trend; their top points all appear in the area of $60 \%$.

When the replacement content was lower than $60 \%$, strength of UHPC mortars increased with the higher replacement content. This is because IOT contain smaller particles; the small particles can reduce the proportion of the larger aggregate to reduce the number and volume of interface transition zone between aggregate and hydration; on the other hand some smaller particles can have a very good filling effect at the same time.

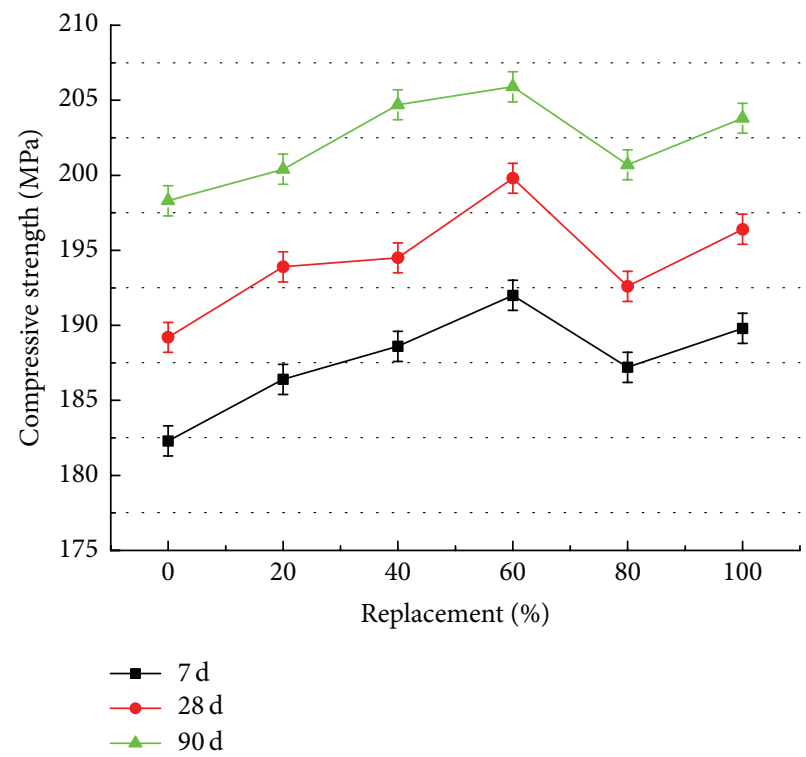

FIgURE 6: IOT of $0.075 \sim 1.18 \mathrm{~mm}$ instead of silica sands. 


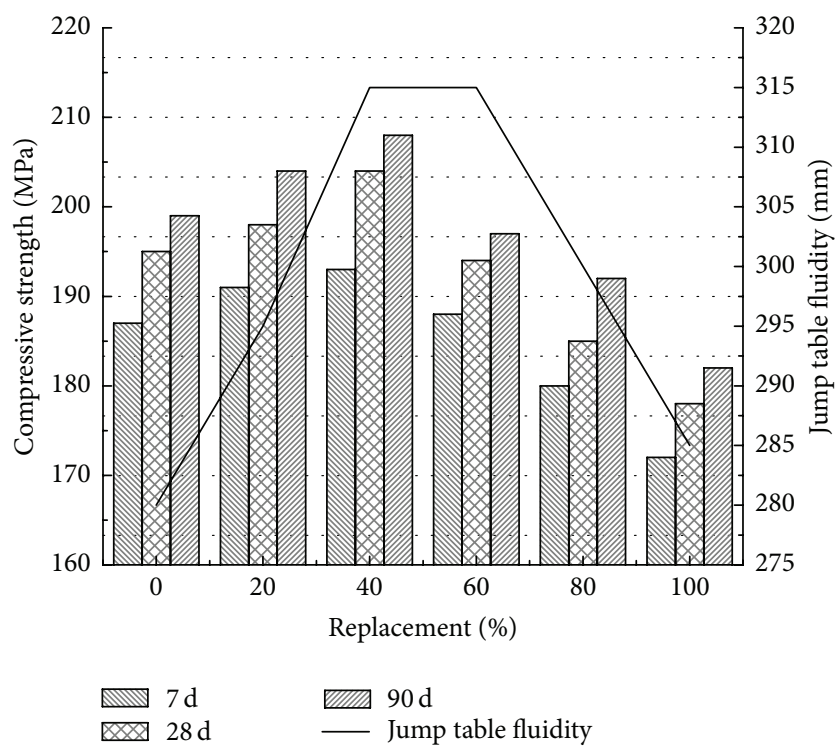

FIGURE 7: Influence of micropowder content on UHPC.

The strength of replacement by $80 \%$ was lower than $60 \%$ which can be explained by the fact that smaller particles need more water to package them which leads to having no enough water for active materials to hydrate. The strength of replacement by $80 \%$ was lower than $100 \%$ which can be explained by the fact that larger quartz sands increase the risk of weak area. However, the micropowder, aggregate size, and grinding of sands work together in concrete; they get the best relationship when replacement content is $60 \%$.

3.4. Influence of Micropowder in IOT on UHPC. Figure 7 shows the influence of micropowder content against the strength and fluidity of UHPC mortars; it shows that at first mountain flour content was low (no more than 4\%); the strength and fluidity of UHPC mortars increased with higher mountain flour content; the strength and fluidity reached the top point when mountain flour content was $4 \%$; the strength and fluidity were promoted by about $7 \mathrm{MPa}$ and $35 \mathrm{~mm}$, respectively. When the content was $6 \%$ the strength became lower but fluidity was constant; the strength and fluidity were lower with higher micropowder content.

It can be explained by the fact that micropowder has several advantages in concrete [11, 12]; (1) grading effect: it can act as microfilling effect; it also can work with cement and fly ash to reduce the pore of concrete and release more free water. (2) Its morphology appearance effect: most of the particles are irregular or sharp-edged; to a certain extent, it can support strength as fine aggregates. (3) Microcrystal effect: reasonable content can accelerate cement hydration. Especially in UHPC, ultra-low water bind ratio and high content of active powder cause less free water and very ropy performance; mountain flour can well release free water for binding and improving its fluidity. At the same time it also has some negative effects, such as too much micropowder content; it sure needs more free water to package it which would lead to reducing the free water of cement hydration.
It also would undermine its effect on optimization of grading; there are studies that have shown that mountain flour is more likely to absorb carboxylic high range water reducing agent than cement which of course affects its performance. On the other hand, micropowder brings some clay powder into UHPC and the clay powder content will be increased with more micropowder; as we know, clay powder is so little and can stick to the surface of aggregates to block the bond of aggregates and set cement which becomes weak link in concrete. The strength of clay is low and its volume will expand after its hardening; it also has a very strong adsorption for carboxylic high range water reducing agent leading to less effective water reducing agent, and the influence is deadly especially in low water bind ratio [13]. Therefore, its disadvantages work as a more important role in UHPC with increasing content of micropowder.

\section{Conclusions}

This paper studied the feasibility of using IOT as fine aggregate to prepare UHPC; the experimental results show that cleaned IOT had negligible poorer performance than silica sands but better performance than river sands at the same grading. The strength of UHPC became higher when the largest particle size of aggregate decreased. When $60 \%$ silica sands were instead by $0 \sim 1.18 \mathrm{~mm}$ IOT as mixed fine aggregate, the UHPC got the best performance and was better than only using silica sands as aggregate. The micropowder was good for the strength and fluidity of UHPC when the content was no more than $4 \%$ but had negative influences with higher content; the content of micropowder of IOT must be controlled strictly in UHPC.

\section{Conflict of Interests}

The authors declare that there is no conflict of interests regarding the publication of this paper.

\section{Acknowledgment}

This work was funded by the Natural Science Foundation Item of China (51372185).

\section{References}

[1] P. Richard and M. Cheyrezy, "Composition of reactive powder concretes," Cement and Concrete Research, vol. 25, no. 7, pp. 1501-1511, 1995.

[2] O. Bonneau, C. Poulin, J. Dugat, P. Richard, and P.-C. Aitcin, "Reactive powder concrete: from theory to practice," Concrete International, vol. 18, no. 4, pp. 47-49, 1996.

[3] B. Gerard, D. Jerome, and B. Arnnud, "The use of RPC in cross flow cooling towers," in Proceedings of the International Symposium on High Performance Concrete and Reactive Powder Concrete, pp. 59-73, University of Sherbrooke, Sherbrooke, Canada, 1998.

[4] P. Y. Blais and M. Couture, "Precast, prestressed pedestrian bridge-world's first reactive powder concrete structure," PCI Journal, vol. 44, no. 5, pp. 60-71, 1999. 
[5] J. Dugat, N. Roux, and G. Bernier, "Mechanical properties of reactive powder concrete," Materials and Structures, vol. 29, no. 188, pp. 233-240, 1996.

[6] H. Zanni, M. Cheyrezy, V. Maret, S. Philippot, and P. Nieto, "Investigation of hydration and pozzolanic reaction in reactive powder concrete (RPC) using ${ }^{29}$ Si NMR," Cement and Concrete Research, vol. 26, no. 1, pp. 93-100, 1996.

[7] J. Matschullat, R. P. Borba, E. Deschamps, B. R. Figueiredo, T. Gabrio, and M. Schwenk, "Human and environmental contamination in the Iron Quadrangle, Brazil," Applied Geochemistry, vol. 15, no. 2, pp. 181-190, 2000.

[8] S. K. Das, K. Sanjay, and P. Ramachandraro, "Exploitation of iron ore for the development of ceramic tiles," Waste Management, vol. 20, pp. 725-729, 2000.

[9] I. Licskó, L. Lois, and G. Szebényi, “Tailings as a source of environmental pollution," Water Science and Technology, vol. 39, no. 10-11, pp. 333-336, 1999.

[10] T. Akçaoğlu, M. Tokyay, and T. Çelik, "Effect of coarse aggregate size and matrix quality on ITZ and failure behavior of concrete under uniaxial compression," Cement \& Concrete Composites, vol. 26, no. 6, pp. 633-638, 2004.

[11] B. Li, M. Zhou, J. Cai, and J. Liu, "Effect of micro fines in manufactured and properties of various strength grade concretes," Concrete, vol. 225, no. 7, pp. 51-57, 2008.

[12] L. Zhang, L. Liu, Y. Zhou, and Z. Wang, "The influences of the content of quartziferous rock powder on the workability and mechanical properties," China Concrete and Cement Products, vol. 12, pp. 22-26, 2011.

[13] F. Sun, X. Sun, L. Yang, and Z. Sun, "Effect of clay content of sand on technical economical index of concrete with polycarboxylic high performance water reducer," Concrete, vol. 256, no. 2, pp. 95-97, 2011. 

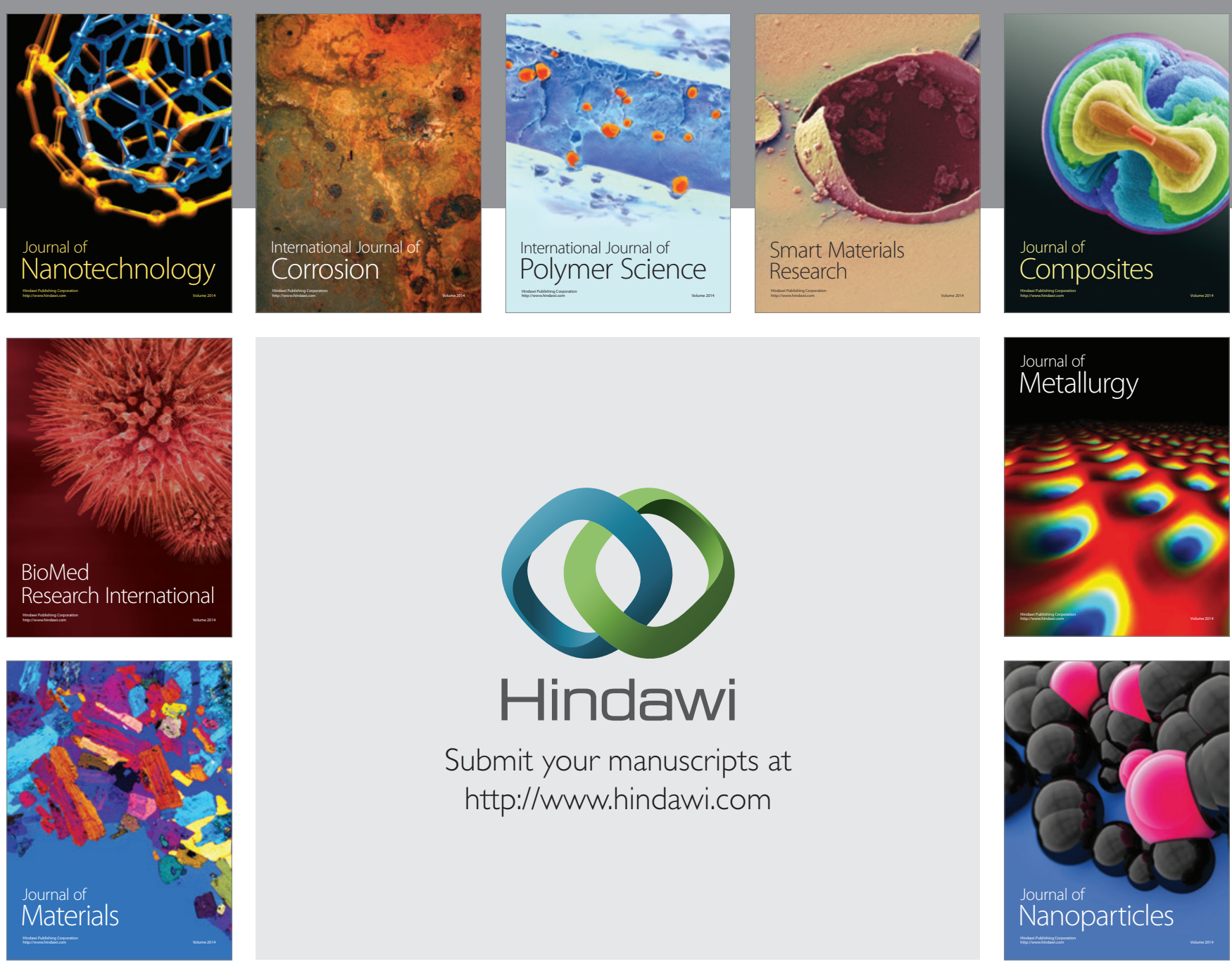

Submit your manuscripts at http://www.hindawi.com
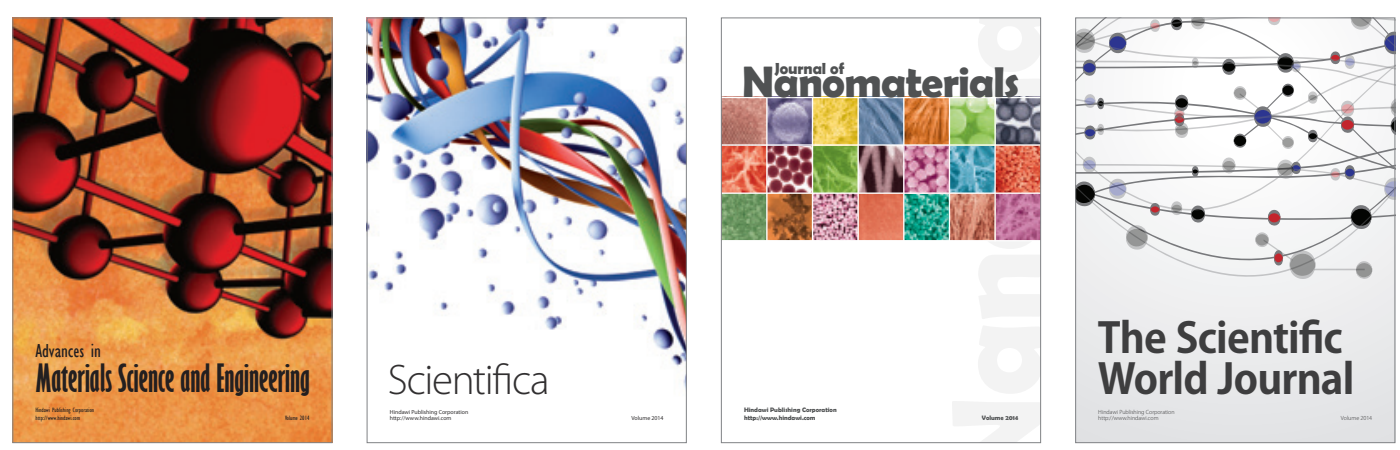

\section{The Scientific World Journal}
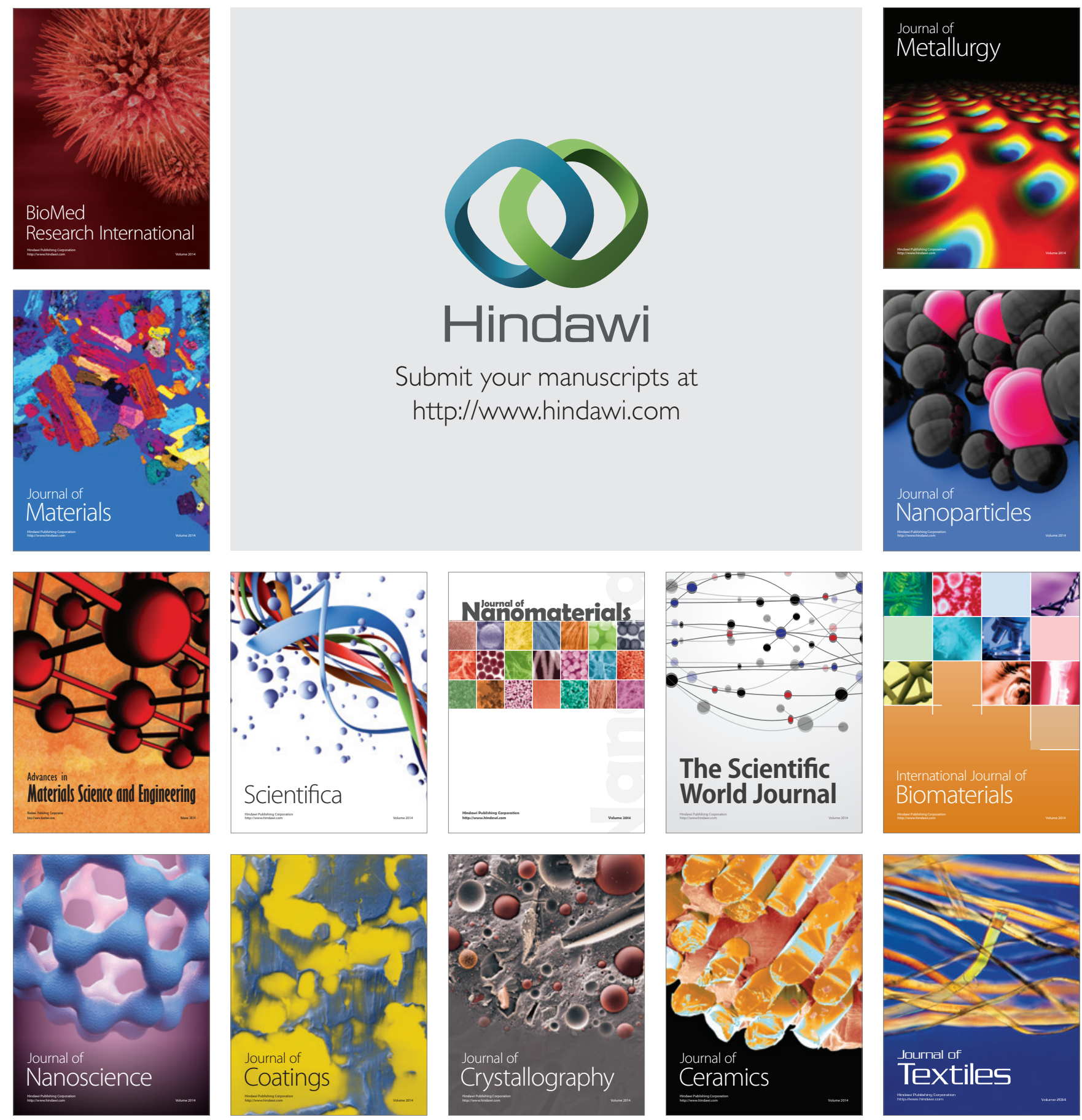